There was present marked hematuria which disappeared in a week's time under irrigations of boric acid. Several of these attacks occurred which responded to the irrigation treatment.

On Feb. 15, the patient was gradually failing and lay couched up in bed with legs flexed as if from great distress. He denied having much pain, but the expression indicated suffering. Took plenty of nourishment in the form of milk, eggs and custard. Passed urine freely which contained albumin and considerable pus. Temperature, $101 \mathrm{~F}$. to $104 \mathrm{~F}$. and pulse small and compressible.

On Feb. 18, the patient died early in the morning. He had had several chills during the preceding few days. His temperature before death ranged from $101 \mathrm{~F}$. to $103 \mathrm{~F}$. A few hours prior to death an enlargement about one and one-half inches in diameter was discovered at the lower margin of the ribs and to the right of the spine, showing slight fluctuation. On aspiration about an ounce of bloody fluid of uriniferous odor was evacuated. Prior to aspiration the patient passed a small amount of bloody urine and with it a long fibrinous clot apparently from the urethra. About the same time he vomited his nourishment the first and only time during his illness. At the brim of the pelvis was noticed puffiness as of extravasation of urine. Death occured apparently from collapse.

Autopsy.-This revealed the following conditions: Rigor mortis well developed. Body emaciated. Slight adhesion at

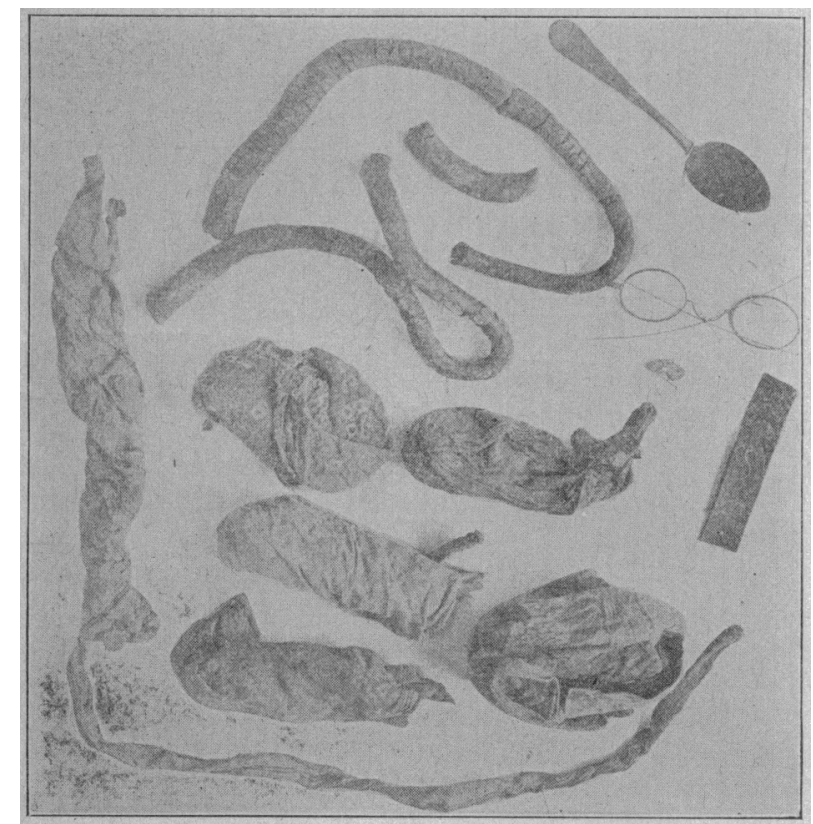

Bandkerch1e1, necktle, rubber tublng and other articles found at autopsy in the stomach of an Insane man.

apices of the lungs which were easily broken up. Lung tissue anthracotic, crepitant and congested. Slight adhesions of liver and stomach to the parietes. Signs of an old general peritonitis. The stomach was very large and contained the following articles: 1 piece of half-inch rubber tubing. 18 inches long; 1 piece of half-inch rubber tubing 14 inches long; 5 large red bandanna handkerchiefs; 1 teaspoon; 1 necktie with scarf-pin in place; 1 pair of spectacles; 1 rodent's skull; 1 piece of rubber band of suspender. In the small intestine was found one arm of the spectacles, the other being located in the abdominal cavity. The combined weight of the collection was 20 ounces.

Although the stomach appeared large and distended, it gave no evidence of its contents prior to the autopsy. There was no suspicion of the patient's peculiar fondness for such articles of diet. Only once was he detected in the act of attempting to swallow a foreign body. This happened to be the watch of a fellow patient. He was caught when placing the watch in his mouth. No particular attention was paid to this at the time other than attributing the occurrence to an aimless act of a dement.

The expression and position of the patient, especially in the latter stages, constantly denoted suffering, though he usually denied the existence of any pain. Throughout the course of his illness his appetite was good and he took sufficient nourishment. As a rule, he was noncommunicative, but occasionally he would smile. The mental aspect of the case was hopeless from the outset. I strongly regard his Polish nativity as a bad mental asset; these cases are not favorable and generally terminate in dementia. The physical condition of the patient was fair and he held up well for some years. Examination of the pupils showed nothing unusual, responding well to light and accommodation and were normal in size and regular in outline. The patella reflexes were slightly diminished.

Referring to the stomach contents as revealed by the autopsy, it is interesting to note that the handkerchiefs were twisted, having the appearance of being wrung out, and it is difficult to conceive how they were able to pass the glottis without the patient's choking. The pieces of rubber tubing gave evidence of having been in the stomach some time, the largest, I should say, at least a year, judging from the action of the gastric juice, which changed the consistency of the rubber to nearly that of putty. The teaspoon was discolored. The necktie and scarf-pin belonged to a fellow patient, who had missed the tie a month before. It was slightly discolored, but otherwise in good condition. The arm of the spectacles, which was found in the abdominal cavity, had penetrated the pelvis of the kidney. The skull of the rodent was well formed and complete. The photograph shows the articles contained in the stomach.

\section{A CASE OF SCROTAL CALCULI.}

\section{HENRY BENJAMIN OERTEL, M.D. President Pueblo County Medical Soclety. PUEBLO, COLO.}

Bistory.-M. S., aged 38, white, had had for four months before I took charge of the case, (Nov. 5, 1906), swelling of and pain in the scrotum, penis and adjacent parts. He had also been troubled with leaking of the urine from two false openings through the penis situated one inch and one and three quarters inches, respectively, from the base. He gave a history of syphilitic infection of eleven montbs standing.

Examination.-His general condition was fair, facial ex pression anxious with normal temperature and exhilarated pulse. There was decided swelling of scrotum and penis and pus exuding from the meatus and the two false openings. The parts were so tender as to make a thorough examination impossible. After three days use of lead water and landanum and codein, examination again was made, which revealed the sharp edge of a hard substance at extreme inferior border of scrotum, just to the left of the median line. The incision was enlarged and the body extracted, which latter proved to be a calculus-probably of calcium oxalate. The pain increased and the pus exuded more freely. The next day the patient was anesthetized, and with the assistance of Dr. J. W. Davis, three more ealculi were removed. Collapse under the anesthetic stopped the operation. The symptoms diminished in severity and three days later the patient again was anesthetized and four more calculi removed. Two of these were in the same location as the first, and two, distinctly oval in shape, were removed from the inferior aspect of the base of the penis.

Postoperative. History.-After the operation, the pain, swelling and suppuration materially decreased. Urine and pus continued leaking from the false openings. One week later another calculus was removed from the scrotum and the false openings were touched with pure phenol (carbolic acid). The 
following day the pain stopped. The swelling gradually subsided, the false openings healed in a few days, suppuration stopped, and one week thereafter patient was discharged. The calculi were all decidedly adherent, necessitating their being torn away. There was no involvement of the tunica vaginalis as the testicles did not enter into the process. Antisyphilitic treatment was continued and the patient had no further trouble. The patient reported April 30, 1907, with no further symptoms.

Seven of these calculi fit well together, forming an ovoid mass $12 \mathrm{~cm}$. by $6 \mathrm{~cm}$. (4\% in. by $25 / 16 \mathrm{in}$.) in circumference. Two calculi from base of penis fit together and measure 9 cm. by $5 \mathrm{~cm}$. ( $3 \frac{1}{2}$ in. by 2 in.) in circumference.

\section{A SIGNAL LANTERN FOR TERTING COLOR BLINDNESS.}

JOHN IZARD MIDDLETON, M.D NEW YORK CITY.

Consideration of several of the present types of lanterns for the above purpose shows them as expensive and complicated. The article, however, here described, while offering little originality, exhibits simplicity and

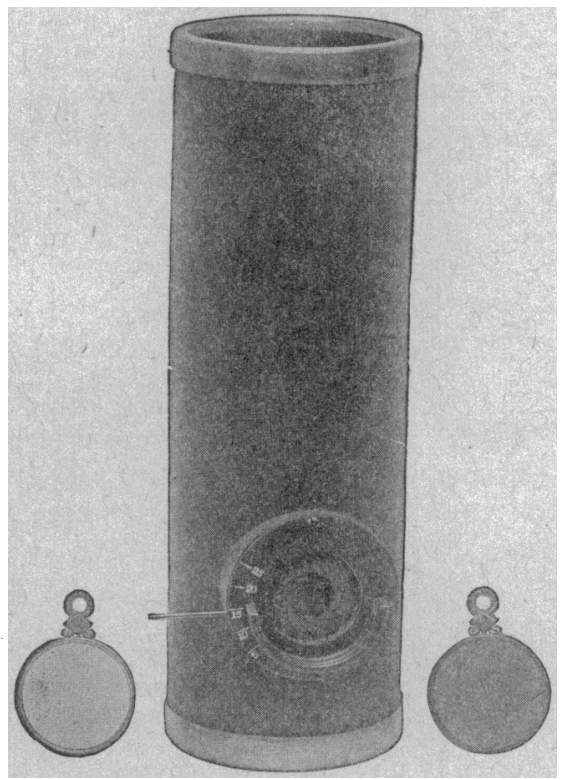

moderate cost, being well within the reach of the mass of examining oculists.

The apparatus consists of a Thorington's asbestos chimney, with iris diaphragm, and a double cell of half a trial frame attached in front of and below the circular opening in the chimney. The light within is either electric or gas; enclosed in a frosted bulb or chimney of an Argand burner.

The glasses $f_{c}$. testing the colors are six in number, four being contained in the usual test-case: The red, the blue, the cobalt blue (for purple) and one for London smoke. This last can also be used in the several varieties furnished by the test-case. The remaining two necessary glasses, not found in the test-case, are: One standard green and one frosted throughout, and they, together with the Thorington chimney as above arranged, represent the extra equipment desired.

To employ the test a signal color is dropped into the cell next to the chimney, and in the forward cell is placed the frosted or else the London smoke glass, the latter thus presenting varying atmospheric conditions.
The quantitative light-perception can be ascertained by working the iris diaphragm on whose side is a millimeter scale, showing the size of the opening admitting light. The additions to the Thorington chimney being light, the test is made easily and quickly and without tilting the chimney. Mr. E. B. Meyrowitz, of New York, has kindly furnished the model on whose working this description is based.

\section{BIRTH OF QUADRUPLETS.}

\section{S. V. WILKING, M.D.}

ROANOKE, IND.

The birth of quadruplets is sufficiently rare ( 1 in $371,126)$ to make of interest the following data regarding a case of this kind:

History.-The mother, aged 36, Irish, weighed 125 pounds and was one of three children born singly. She had been married 14 years and this was her eleventh pregnancy. In all of her previous pregnancies she had gone to term with the exception of two, in which she aborted. Three of her children had been stillborn, one of these being a breech presentation.

The father, aged 40, American, was one of seventeen children, all born singly.

Labor was rapid and the delivery, which was exceptionally easy, occurred May 30,1907. The weight and sex of each child was as follows: First, 2 pounds $15 \frac{1}{2}$ ounces, female; second, 2 pounds 12 ounces, female; third, 2 pounds 151/2 ounces, male; fourth, 2 pounds 15 ounces, female. None of the infants had any visible malformation and development in each seemed com. plete. The fourth child lived two and one-half bours; the first, three hours; the third, thirty hours, anu the second was still living six days after birth, with fair prospects.

The placenta after delivery was grossly in two parts, but later examination seemcd to indicat that there was a membranous connection, probably torn during labor. The first (smaller) part presented nothing unusual except that it was smaller than the average placenta, weighing with the membrane, 11 ounces. The second portion weighed 22 ounces and was divided into two parts, the smaller resembling the one just described except that the membranous connection with the larger part was unbroken. The larger part of the second portion was itself divided into two parts connected by placental tissue-possibly a placenta succenturiata. There was a separate amnion for each child.

Suggestions on Medical Inspection.-The governor of Massachusetts recently appointed a committee to prepare a circular of advice to the school physicians of the state to aid them in performing their duties under the lately enacted law requiring medical inspection of school children. We are indebted to Dr. Robert W. Lovett, Boston, for a copy of this pamphlet. The law requires the inspection of each school child at least once a year to determine whether he is suffering from any disability tending to prevent his receiving the full benefit of his school work, or requiring a modification of the school work in order to prevent injury to the child or to secure the best educational results. The information contained in the circular has been furnished by representative medical specialists of the state so that it represents the highest professional authority. The circular is suited to the use of teachers as well as school physicians and contains suggestions which will prove very valuable to them in detecting cases among the school children that afford reasonable suspicion of being affected with infectious diseases, or diseases or defects of the eye, ear, nose, skin, bones, teeth, or the nervous system. Sections on school inspectors, school furniture and school hygiene are added. The pamphlet may afford some valuable suggestions to school authorities who may desire to establish some form of school inspection even if it is not required by law. 